\title{
New Approach for Collecting Cancer Patients' Views and Preferences Through Medical Staff
}

This article was published in the following Dove Press journal:

Patient Preference and Adherence

\author{
Tomoko Takayama $\mathbb{D}^{\prime}$ \\ Yoji Inoue' \\ Rie Yokota $\mathbb{D}^{2}$ \\ Masayo Hayakawa' \\ Chikako Yamaki' \\ Yasushi Toh ${ }^{3}$ \\ 'Cancer Information Service Division, \\ Center for Cancer Control and \\ Information Services, National Cancer \\ Center, Tokyo, Japan; ${ }^{2}$ Department of \\ Health Communication, Graduate School \\ of Medicine, The University of Tokyo, \\ Tokyo, Japan; ${ }^{3}$ National Hospital \\ Organization, Kyushu Cancer Center, \\ Fukuoka, Japan
}

\begin{abstract}
Purpose: It is crucial for health professionals to understand patients' and families' views and preferences (PVPs) to enhance their adherence to treatments and subsequent satisfaction. Regularly and consistently collecting comprehensive information on the needs and concerns of patients/families and utilizing the information is vital for improving clinical practice and the healthcare environment. As an initial approach, this study aimed to develop a new system for appropriately collecting PVPs regarding cancer from nationwide medical staff and consider the potential utilization of PVPs in clinical practice.
\end{abstract}

Methods: Web-based anonymous surveys were conducted with medical staff in nationwide cancer care hospitals in Japan. The surveys queried the questions, values, desires, and experiences expressed by cancer patients or their families on five topics, namely two cancer sites (colorectal and esophageal cancers) and three symptoms and signs (lymphedema, urinary symptoms, and tingling/ numbness/pain) within the past year. The PVPs were compared to the five topics and staff medical specialties, and those on tingling/numbness/pain were analyzed qualitatively.

Results: Among the 904 medical staff who responded to this survey, the PVPs encountered by the staff differed according to the topic and staff medical specialty. Tingling/numbness/ pain was the most frequently encountered symptom, and urinary symptoms were the least encountered. Only half or fewer of the medical staff had information available regarding urinary symptoms and tingling/numbness/pain. Further, qualitative content analysis of the expressed PVPs regarding tingling/numbness/pain raised clinical questions on this topic that led to the construction of a "Questions \& Answers" section on a public website in Japan.

Conclusion: This study suggests that collecting PVPs through nationwide cancer-related medical staff might be an efficient way to understand the specific requirements of patients/ families. It would also be possible to document PVP trends according to changes in the environments of patients/families by nationwide, consistent, and continuous PVP collection. Keywords: patient's needs, cancer information, health communication, quality of health care, trends in patients' preferences

\section{Plain Language Summary}

Understanding cancer patients' and their families' views and preferences (PVPs) regarding treatment and care helps improve the quality of services provided to them. It is important to collect a wide range of PVPs regularly, consistently and in a timely manner, to develop policies and treatment responses accordingly. This study explored a new approach for collecting PVPs regarding cancer treatment and care, by surveying medical staff about the PVPs they encountered in clinical practice. This is the first step to establish a sustainable nationwide system to collect cancer-related PVPs and to utilize them in clinical practice.

The medical staff provided information not only regarding the PVPs related to five different topics (including types, signs, and symptoms of cancer) they had encountered,
Correspondence: Tomoko Takayama Cancer Information Service Division, Center for Cancer Control and Information Services, National Cancer Center, 5-I-I, Tsukiji, Chuo-Ku, Tokyo, 104-0045, Japan

Tel +8I-3-3542-25I I Ex. I62I

Fax +8I-3-3547-8577

Email totakaya@ncc.go.jp
Patient Preference and Adherence 2021:15 375-385 in $\mathbf{P}$ 
but also regarding their actual responses to these PVPs. The PVPs encountered differed according to the topic and staff specialty. Content analysis of one of the five topics as representative, namely tingling/numbness/pain, led to the development of clinical questions asked by many patients/families, and the provision of such answers to the public by abstracting keywords and concrete means of expression from PVPs. Despite being an indirect way of collecting PVPs, this method was useful for identifying the most commonly encountered PVPs for each specified topic, as well as any gaps in the information available to the medical staff for responding effectively to these PVPs.

\section{Introduction}

To enhance patients' adherence to treatments and their subsequent satisfaction, it is crucial for health professionals to understand the patients' and families' views and preferences (PVPs). ${ }^{1-3}$ Understanding PVPs allows health professionals to provide patients and their families (patients/families) with the necessary information and appropriate treatments and care. However, PVPs vary in terms of treatment-related topics, such as the treatment plan, ${ }^{4}$ possible side effects, ${ }^{5}$ psychosocial topics, ${ }^{6,7}$ daily activities, ${ }^{8}$ and personal values. ${ }^{9}$ In the rapidly progressing medical environment, health professionals are likely to be required to respond to novel PVPs without any supporting information. ${ }^{10}$ Therefore, it is important to understand current PVP trends and to collect comprehensive information on these trends consistently and in timely manner. Furthermore, collecting PVPs in clinical practice is expected to enhance the quality of medical environments because it will lead to developing new approaches to unmet PVPs, resulting in effective and reliable communication between medical staff and patients/families. Utilizing the collected PVPs to raise clinical questions in various medical fields will also lead to new evidence regarding medical conditions.

However, it is difficult to collect PVPs in timely manner or at a national level through nationwide or wide-range questionnaire surveys. It is also necessary to collect PVPs repeatedly to develop and evaluate a national policy for specific diseases such as cancer. ${ }^{11,12}$ Collecting PVPs through nationwide disease-specific medical staff who take care of patients/families within clinical practice is one possible solution to the aforementioned problems. In actual clinical practice, the symptoms, distress, burdens, or problems are not always explicitly expressed by patients/ families, ${ }^{5}$ but they are more likely to be expressed during casual conversations or interactions with medical staff. ${ }^{13}$
The expressions of concern are likely accompanied by discussions regarding patients'/families' experiences in their daily activities, and their views and preferences. ${ }^{14}$ The interactions between patients/families and medical staff can occur in various settings such as at the reception, in examination areas, or in outpatient or inpatient settings, and may range from short conversations to long discussions. Any medical staff member, including physicians, has the opportunity to meet and interact with patients/ families in various clinical settings. Medical staff should be sensitive to, and aware of, patients'/families' symptoms and burdens and adequately guide them toward further symptom management or care. ${ }^{14}$

Nevertheless, collecting PVPs promptly and widely from various patients has not yet been researched. In addition, a specific method to utilize PVPs in a nationwide clinical practice has not been examined sufficiently. The most appropriate group from whom cancerrelated PVPs can be promptly and widely collected are medical staff working in nationwide cancer-specialized hospitals, which are designated based on the government's national cancer policy and execute advanced cancer treatment and care. These medical staff are required to adequately and precisely respond to such PVPs. The aim of this study is to develop a new system for appropriately collecting PVPs regarding cancer from nationwide medical staff and consider the potential utilization of PVPs in clinical practice. We obtained PVPs expressed to various medical staff in the nationwide hospitals designated by the Japanese government (designated cancer care hospitals: DCCHs). At the initial stage of this study, we chose five cancer-related topics that were anticipated to be associated with a diversity of PVPs. We also selected one of the five topics - the sensation of tingling, numbness, and pain (henceforth, tingling/numbness/pain) — to qualitatively analyze the content of the expressed PVPs in detail and to discuss the potential utilization of PVPs in clinical practice.

\section{Methods}

\section{Participants}

We conducted a web-based multicenter cross-sectional questionnaire survey of medical staff in DCCHs in Japan during the period of July to September 2018. Participants were recruited from two groups of staff. The first consisted of medical staff (physician, pharmacist, nurse, physical/ occupational/speech therapist, radiation/clinical laboratory 
technologist, dietitian, clinical psychologist, social worker, cancer counselor, and medical clerk) from 32 hospitals belonging to the Japanese Association of Clinical Cancer Centers (JACCC) among 434 DCCHs in Japan. ${ }^{15}$ The second consisted of cancer counselors in Cancer Information and Support Centers (CISCs) located in all DCCHs. One of the unique features of the CISCs as compared to other typical hospital functions is that anyone, regardless of holding a hospital identification number or not, can access a CISC and obtain reliable cancerrelated information and support for adequate referrals without any charge. ${ }^{16}$ Cancer counselors with predominately nursing and social-work backgrounds are stationed in the CISCs. In this study, we considered cancer counselors as a separate medical staff category from other medical specialties.

\section{Collecting PVPs from the Medical Staff}

To recruit medical staff, an email was sent to the secretariat division of the JACCC, and each hospital secretariat division forwarded the email to medical staff in each hospital. To recruit the cancer counselors, an email was sent to directly to the cancer counselors of 434 CISCs through a mailing list. Only medical staff and cancer counselors who agreed to participate in the study responded to the web-based questionnaire, whose data were transferred directly and anonymously to the Cancer Information Service Division, Center for Cancer Control and Information Services, the National Cancer Center (NCC-CIS), Japan.

In this study, we operationally defined PVPs as questions, values, desires, and experiences expressed to medical staff by patients/families in various medical situations. To collect PVPs, we developed three questions for medical staff based on their interaction with patients/families ${ }^{17}$ that were used to investigate each topic, as follows. (1) "Within the past year, did you receive any questions from your patients and/or their families about each of the five topics described below? Yes or No?" If the answer was "Yes," they were further asked to (2) describe the question or share information in an open-ended manner and were asked (3)"Did you have any source of information such as clinical practice guidelines, booklets published by a public organizations or companies, etc. on responding to the patient/family regarding the topic? Yes or No?" We designed the questions to be as simple as possible and to represent minimal burden on the participants.
As this study focused on the indirect experiences of medical staff rather than direct collections of PVPs, we needed to understand if this process was sufficiently sensitive to collect PVPs depending on the topic. Therefore, at the initial stage of the study, we chose five topics that were anticipated to have diverse PVPs and collected the PVPs for each topic indirectly. Regarding cancer sites, we chose colorectal cancer and esophageal cancer. Colorectal cancer is the most prevalent cancer type in Japan; there is an associated national screening program and this type of cancer has a relatively favorable prognosis. Esophageal cancer is a type of cancer with the worst prognosis, and there is no cancer screening program for this cancer site in Japan. $^{18}$ These differences create differences in public knowledge and resultant PVPs. We chose three symptoms-lymphedema, urinary symptoms, and tingling/ numbness/pain - to assess the effectiveness of collecting the PVPs through medical staff because the symptoms involved different degrees of difficulty in their assessment by a third person.

\section{Data Analysis}

This study used a quantitative and qualitative mixedmethods design. The number of medical staff who encountered PVPs and those who had related information on the topics were compared among the five topics. Then, we statistically compared the medical staff's experience of PVPs and possession of available information on each topic by their medical specialties using the Chi-square method.

In this report, we analyzed the statements regarding tingling/numbness/pain qualitatively, as representative of the potential utilization of PVPs. Free-text statements were analyzed by two authors (TT and RY) with expertise in cancer care and heath communication perspectives. The statements of the patients/families reported by the participants were analyzed using an inductive approach via conventional content analysis, ${ }^{19}$ as follows. (1) The statements were repeatedly read by two researchers to obtain a sense of the whole and the statements were divided into several sentences as necessary, if the free-text answers had more than one meaning. (2) Each statement was qualitatively coded by capturing its core meaning, and those with similar meanings were organized into subcategories based on how they were related. Seven categories were abstracted from the subcategories' inter-relationships with reference to several preceding studies of unmet needs or patients' preferences with respect to cancers. ${ }^{5,20,21}$ (3) Each 
statement was categorized one of seven categories: 1) cause and prevention, 2) symptoms, 3) prognosis, 4) treatment, 5) self-management, 6) daily life, and 7) unclassified statements, such as those referring to thoughts, hopes, emotions, and so forth. The frequencies of responses in each category were calculated. All responses were then independently double-coded. In case of discordance in double codes, discussion and negotiation between the two authors continued until a consensus was reached. A total of 940 statements were coded into 44 initial categories, subcategorized into 23 categories, and classified into the seven final categories.

Sociodemographic information was also collected, including sex, age, length of clinical experience, and medical profession. We also investigated the time required to complete the questionnaires from login to logout times on the medical staff's personal computers to judge the future sustainability of this survey.

\section{Developing Clinical Questions Regarding Tingling/Numbness/Pain}

We developed clinical questions to produce questions and answers ( $\mathrm{Q} \& \mathrm{~A}$ ) regarding tingling/numbness/pain primarily for patients newly diagnosed with cancer or who had recently received treatments. Based on the PVPs related to tingling/numbness/pain identified by the qualitative content analysis, clinical questions for which patients/families strongly desired answers but which were difficult for medical staff to answer were developed by members of the NCC-CIS including two authors (TT and $\mathrm{MH})$. The NCC-CIS provided the public with these questions and corresponding answers through the largest cancer information site in Japan (https://ganjoho.jp/public/index. html). We considered that the questions with higher priority should cover a wide range of categories, high frequency of PVPs, and PVP content that patients/families find difficult to discuss with medical staff, even if infrequently expressed. Concrete words or expressions from PVPs were included in the questions to the extent possible.

This study was conducted in accordance with the Ethical Guidelines for Medical and Health Research Involving Human Subjects of Japan. Medical staff belonging to the JACCCs and cancer counselors of the CISCs were informed of this study in writing. Their voluntary responses to the questionnaire were regarded as consent to participate in the study. The Medical Ethical Committee of the National Cancer Center, Tokyo, Japan, ruled that no formal ethical approval was required for this study (reference number 6000-017).

\section{Results}

We collected a total of 904 responses; Table 1 illustrates the demographic and clinical characteristics of respondents. Approximately $70 \%$ of the respondents were female, and $40 \%$ had more than 20 years of clinical experience. The largest proportion of the respondents were nurses (onefourth), followed by physical/occupational/speech therapists and radiation/clinical laboratory technologists, physicians, and cancer counselors. The average duration required to

Table I Demographic and Clinical Characteristics of Respondents

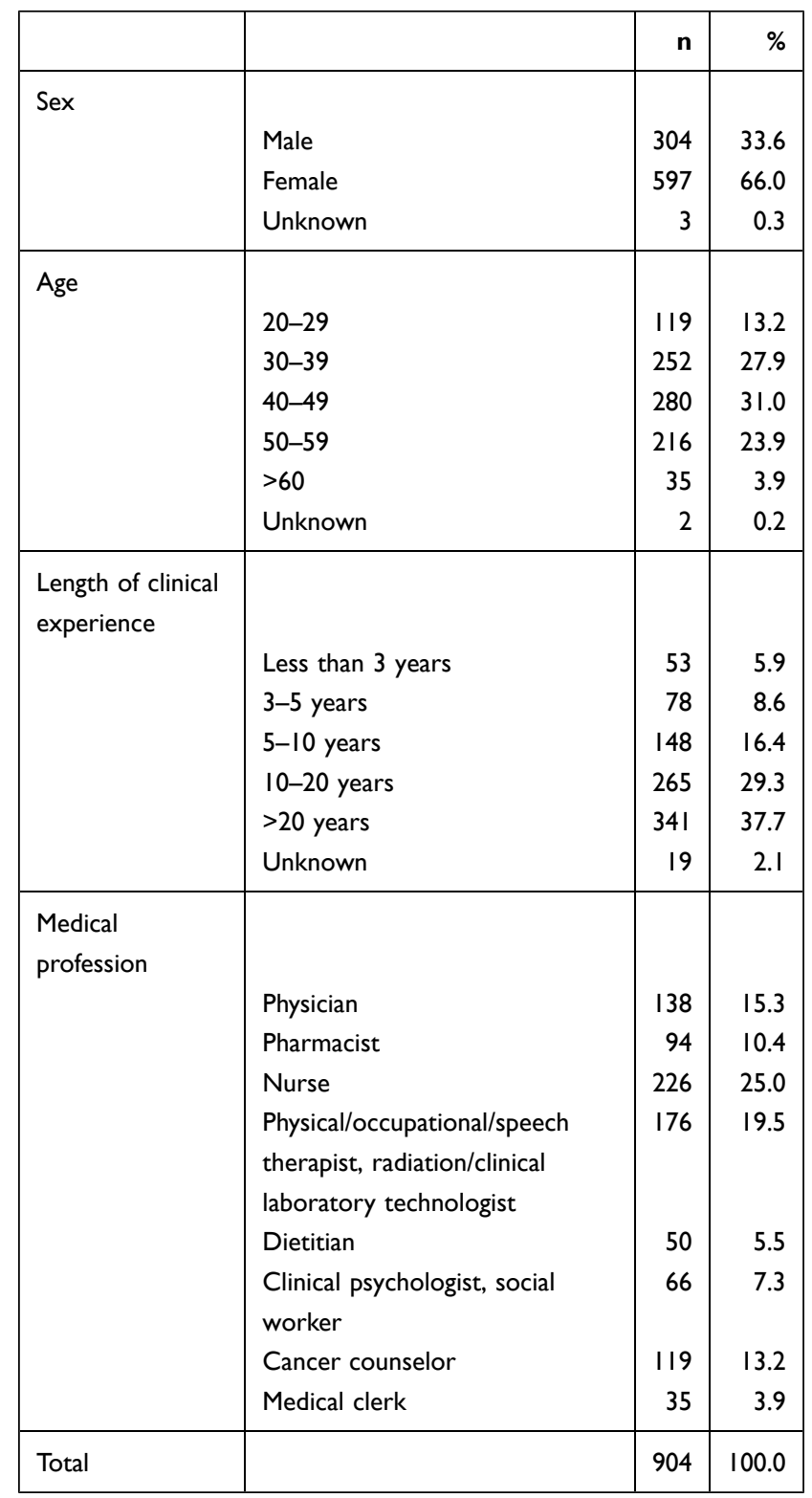


complete the questionnaires was 15.8 minutes (standard deviation $=23.8$ ), and the median time was 9 minutes, suggesting the survey was sustainable.

Table 2 illustrates the medical staff's experiences of receiving PVPs and the presence/absence of available information related to the PVPs. Among the five topics, the most number of PVPs were about tingling/numbness/ pain, and the least were related to urinary symptoms (63.3\% and $35.1 \%$, respectively). More than $70 \%$ of the medical staff had some available information regarding colorectal cancer and lymphedema when they needed to respond to patients/families, whereas only half or less of them had information regarding urinary symptoms and tingling/numbness/pain.

The frequency of experiencing PVPs according to medical specialty of the staff is illustrated in Table 3. The frequencies of PVPs varied by topic depending on the medical specialty ( $p<0.0001)$. For example, the PVPs regarding colorectal and esophageal cancers were most frequently expressed to dietitians; PVPs regarding lymphedema and tingling/numbness/pain were most frequently expressed to cancer counselors and pharmacists, respectively; while urinary symptom PVPs, although rarely encountered, were most frequently expressed to nurses and cancer counselors. Cancer counselors received PVPs on all topics with relatively high frequencies. Table 4 illustrates the presence/absence of information resources that the medical staff used practically when they received PVPs according to their specialty. The percentage of the presence of information resources by topic varied depending on the medical specialty $(\mathrm{p}<0.0001)$. Among the eight medical specialties, cancer counselors most frequently had information available on all five topics. However, only $63.8 \%$ of cancer counselors had information available on urinary symptoms.

Table 5 illustrates the results of the content analysis of the tingling/numbness/pain PVPs. Among the seven categories of this topic, patients/families expressed their PVPs the most and the second most frequently regarding prognosis and selfmanagement, respectively. Representatives of PVPs in each category are also illustrated in Table 5. Although unclassified and infrequent, there remained important PVPs, such as "How much must I endure numbness to continue treatment?" and "Will this numbness be a trade-off for life?"

Table 6 shows nine questions developed from the tingling/numbness/pain PVPs, consisting of 1 to 3 questions in each of six categories, except the unclassified category. The Q \& A was uploaded to the NCC-CIS website in Japanese. ${ }^{22}$

\section{Discussion}

It is important to collect PVPs reflecting issues at a specific time regularly, consistently, and continuously, considering the current circumstances of the rapid appearance of a broad range of new medicines and treatment options. Therefore, we obtained cancer-related PVPs, including questions, values, desires, and experiences, via medical staff with different specialties in nationwide cancer-specialized hospitals. In this study, we collected cancer-related PVPs across five topics and observed differences in staff experiences of PVPs, depending on the topics and the medical specialty of the staff member.

A difference in the number of PVPs was observed across the five topics, which may be due to several reasons. First, the topics for which the medical staff encountered PVPs less frequently might be those that patients/families felt reluctant or uncomfortable to express. Previous studies have demonstrated that the general public often hesitates to talk about topics such as sexuality and egestion, ${ }^{23}$ and medical specialists are also reluctant to talk about these topics. ${ }^{24,25}$ Patients/ families are more reluctant to express their symptoms or burdens concerning these topics, even to their physicians and nurses, especially if either group is less prepared to discuss these topics.

Table 2 Medical Staff's Experience of Patients' Views and Preferences and Possession of Available Information on the Topic

\begin{tabular}{|c|c|c|c|c|}
\hline & \multicolumn{2}{|c|}{$\begin{array}{r}\text { Number of Medical Staff Who Encountered PVPs } \\
\text { within the Past Year }(n=904)\end{array}$} & \multicolumn{2}{|c|}{$\begin{array}{r}\text { Number of Medical Staff Who Had Related } \\
\text { Information on the Topics }(n=904)\end{array}$} \\
\hline & $\mathbf{n}$ & $\%$ & $\mathbf{n}$ & $\%$ \\
\hline Colon cancer & 404 & 44.7 & 296 & 73.3 \\
\hline Esophageal cancer & 333 & 36.8 & 222 & 66.7 \\
\hline Lymphoedema & 399 & 44.1 & 284 & 71.2 \\
\hline Urinary symptoms & 317 & 35.1 & 143 & 45.1 \\
\hline Tingling/numbness/pain & 572 & 63.3 & 286 & 50.0 \\
\hline
\end{tabular}




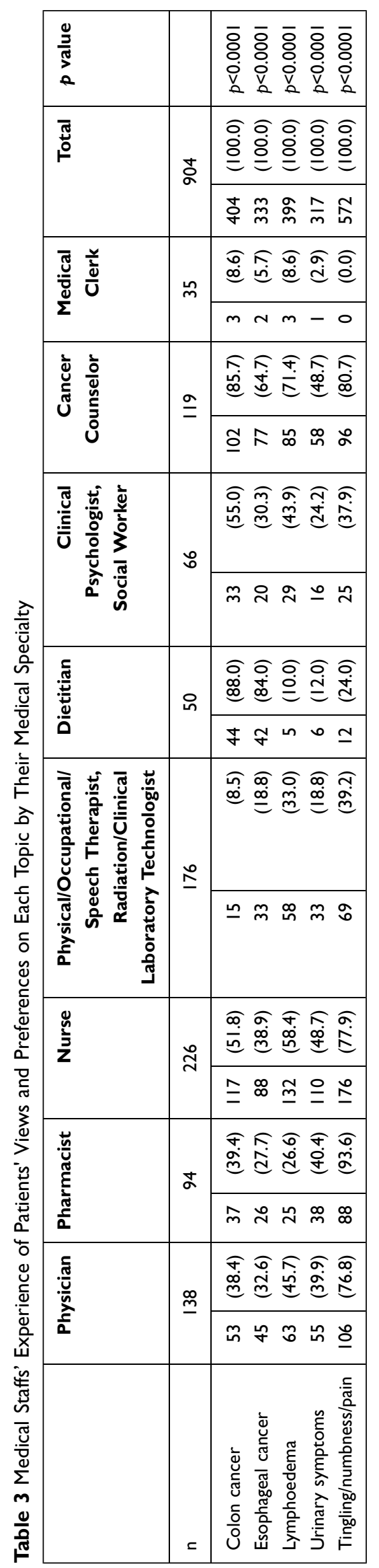

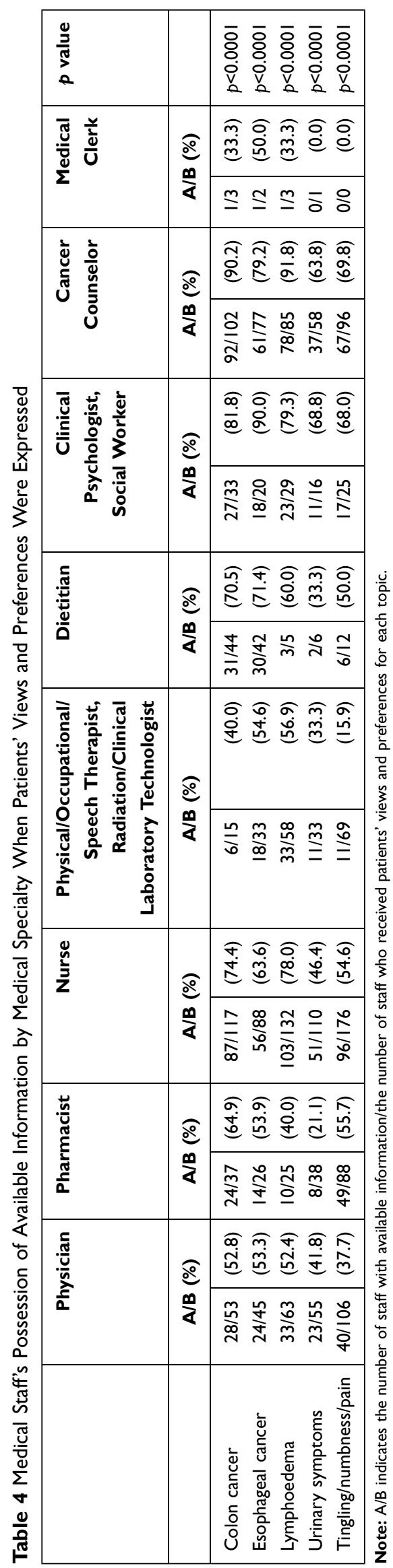


Table 5 Representative Patients' Views and Preferences for Each Category Under "Tingling/Numbness/Pain"

\begin{tabular}{|c|c|c|c|c|}
\hline Category & Sub-Category & Representative PVPs & $\mathbf{n}$ & $\%$ \\
\hline $\begin{array}{l}\text { I) Cause and } \\
\text { prevention }\end{array}$ & $\begin{array}{l}\text { - Looking for information how to prevent the numbness. } \\
\text { Questions about mechanisms and cause of numbness (cancer, surgery, } \\
\text { bone metastasis, diabetes, meal, and so on). } \\
\text { Questions about numbness changes from day to day and/or day and } \\
\text { night. }\end{array}$ & $\begin{array}{l}\text { Is there any way to prevent numbness? } \\
\text { Is numbness due to anti-cancer medications or } \\
\text { does it come from cancer itself? } \\
\text { Why does numbness vary from day to day? }\end{array}$ & 88 & 9.4 \\
\hline 2) Symptoms & $\begin{array}{l}\text { - Description of kinds of symptoms (intensity, frequency, progression, } \\
\text { timing of symptom development, or changes in symptoms) in various } \\
\text { area of body. } \\
\text { - Description of the symptoms (numbness, tingling and pain), and the } \\
\text { effects on daily life. } \\
\text { - Description of the subsequent anxiety, pain, hardship in daily life due } \\
\text { to numbness. }\end{array}$ & $\begin{array}{l}\text { Limbs are numb and painful. } \\
\text { The soles of the feet are spongy and it is difficult to } \\
\text { walk. } \\
\text { I am worried I will make a mistake when operating } \\
\text { my computer because of the numbness. }\end{array}$ & 145 & 15.4 \\
\hline 3) Prognosis & $\begin{array}{l}\text { - Whether numbness can be cured or not. } \\
\text { - How long must I endure numbness until it is cured. } \\
\text { - How long numbness will persist. } \\
\text { - Whether numbness is getting worse or better. }\end{array}$ & $\begin{array}{l}\text { Will numbness be cured or not? } \\
\text { When will the numbness heal? } \\
\text { How long will the numbness persist? } \\
\text { Does numbness gradually reduce? }\end{array}$ & 318 & 33.8 \\
\hline 4) Treatment & $\begin{array}{l}\text { - Questions about the effectiveness of treatment of numbness. } \\
\text { approaches to treat numbness. } \\
\text { - Concerning whether numbness improves by changing and/or stopping } \\
\text { anti-cancer medications. }\end{array}$ & $\begin{array}{l}\text { Is there any medicine for numbness? } \\
\text { I heard that Kampo is effective, but is it true? } \\
\text { Will numbness disappear after anti-cancer drugs } \\
\text { are stopped? }\end{array}$ & 102 & 10.9 \\
\hline 5) Coping & $\begin{array}{l}\text { - Looking for any way to relieve symptoms. } \\
\text { - Looking for any place or people to ask for help. } \\
\text { - How to explain the symptoms to people around me. }\end{array}$ & $\begin{array}{l}\text { How does numbness get better? } \\
\text { Is it better to apply warm or cool compress? Is } \\
\text { massage effective? Is there any food that works for } \\
\text { numbness? } \\
\text { I do not know how to tell my doctor and other } \\
\text { people about my invisible symptoms. }\end{array}$ & 203 & 21.6 \\
\hline 6) Daily life & $\begin{array}{l}\text { - Description of daily life activities affected by the numbness. } \\
\text { - Description of kinds of effects in daily life. } \\
\text { - Looking for solutions, including self-care to relieve symptoms. }\end{array}$ & $\begin{array}{l}\text { I cannot cook because I cannot grasp the knife. } \\
\text { Numbness lasts for a long time, affecting work. } \\
\text { Is there anything I can do to relieve symptoms in my } \\
\text { daily life? }\end{array}$ & 57 & 6.1 \\
\hline \multirow[t]{2}{*}{$\begin{array}{l}\text { 7) Unclassified } \\
\text { thoughts, hopes and } \\
\text { emotions }\end{array}$} & $\begin{array}{l}\text { - Looking for information about people with similar numbness and their } \\
\text { way of coping. } \\
\text { - Thoughts of continuation or discontinuation of anti-cancer } \\
\text { medications. } \\
\text { - Hopes for new drugs, and new ways of dealing with the symptoms. } \\
\text { - Emotions and voices of the heart. }\end{array}$ & $\begin{array}{l}\text { Are there other patients with numbness like me? } \\
\text { How much must I endure numbness to continue } \\
\text { anti-cancer medications? } \\
\text { If someone developed a silver bullet, they would } \\
\text { deserve the Nobel Prize. } \\
\text { Will this numbness be a trade-off for life? }\end{array}$ & 27 & 2.9 \\
\hline & & & 940 & 100.0 \\
\hline
\end{tabular}

Abbreviation: PVPs, patients' views and preferences.

Second, the differences in PVP frequencies might be attributable to the characteristics of the symptoms. For example, urinary symptoms are likely caused by a specific kind of cancer or its treatment, ${ }^{26-28}$ as well as by the aging process and other reasons unrelated to cancer. $^{29,30}$ Therefore, patients may deem it unnecessary to report urinary symptoms to their physician and other medical staff. However, PVPs regarding urinary symptoms were reported by nearly half of nurses and cancer counselors (Table 3), suggesting that these specialties could be expected to collect such PVPs from patients/ families by approaching them with awareness of this problem and thereby enhancing patient satisfaction by addressing their queries.

The accessibility of medical staff may be another reason for the difference in PVP frequencies. Cancer counselors at the CISCs had the most experiences of receiving PVPs and had more information available about all five 
Table 6 Questions Developed from the PVPs Concerning "Tingling/Numbness/Pain”

\begin{tabular}{|l|l|}
\hline Category & Questions* \\
\hline I) Cause and prevention & What is the cause of tingling/numbness/pain? \\
\hline 2) Symptoms & What kinds of symptoms are caused by peripheral neuropathy? \\
\hline 3) Prognosis & How long will tingling/numbness/pain last? Will it persist forever? \\
\hline 4) Treatment & Are there any medicines to cure tingling/numbness/pain? \\
\hline 4) Treatment & $\begin{array}{l}\text { How much can I expect relief from tingling/numbness/pain by treatment? } \\
\text { When my pain is too severe and not relieved, and I am wondering whether I should continue my anti-cancer } \\
\text { medication or not, what should I do? }\end{array}$ \\
\hline 5) Coping & How can I explain my tingling/numbness/pain to people around me? \\
\hline 5) Coping & Is there anything that people around the patient can do? \\
\hline 5) Coping/6. Daily life & I have trouble in my daily life caused by tingling/numbness/pain. Are there any solutions? \\
\hline 6) Daily life & Could you give me any advice for improving my daily life? \\
\hline
\end{tabular}

Notes: *Questions were developed from the PVPs. Answers are available on the website of the Center for Cancer Control and Information Services, the National Cancer Center (NCC-CIS), in Japanese: https://ganjoho.jp/public/support/condition/peripheral_neuropathy/pnqa.html.

Abbreviation: PVPs, patients' views and preferences.

topics than did other medical staff. As regular check-ups become gradually less frequent after the main treatments are completed, it might be difficult for patients/families to maintain frequent contact with their physicians and nurses. Research has also demonstrated that most of patients' unmet needs are expressed after their main treatment is completed. ${ }^{5}$ However, patients/families can use CISCs freely and contact cancer counselors whenever required. ${ }^{16}$ Thus, this demonstrates that it is important for patients/families to have resources that they can spontaneously access with ease, such as CISCs.

Although the most frequent PVP was tingling/numbness/ pain, only half of the medical staff had the necessary information on this symptom (Table 2). This may indicate that the PVPs regarding these symptoms were expressed to a wide variety of medical staff, thereby suggesting that an insufficient response was conveyed to the patients/families. Moreover, it also indicates that there was a lack of adequate information available to the medical staff. This has been indicated in the literature, which has demonstrated that evidence and treatments on this topic are rarely established. ${ }^{31,32}$ The gap between the high frequency of PVPs and the lack of practical information concerning symptoms identified in this study demonstrates the need to find evidence by developing specific clinical questions, which can then be used to establish evidence-based clinical practice guidelines.

Regarding potential utilization of the PVPs, we developed clinical questions based on the results of qualitative content analysis of the tingling/numbness/pain PVPs. While developing the questions, the frequencies of the PVPs were considered, and it was very useful for both patients/families and medical staff that keywords and expressions from the PVP statements in the Questions and Answers (Q \& A) document were included. The resulting Q \& A information was made available to the public through a website based on the results of content analysis of the PVPs. ${ }^{22}$ This is one example of establishing a system to collect and utilize PVPs from nationwide cancer-related professionals who directly interact with patients/families in clinical practice, in a regular, systematic, and timely manner.

Although some electronic collection trials have begun, collecting PVPs directly from patients/families requires considerable effort and is often time consuming. ${ }^{33,34}$ Furthermore, it is often difficult or sometimes impossible to collect PVPs about common symptoms of various diseases and from patients with rare cancers or in a critical condition. Therefore, although the method is indirect, collecting PVPs via medical professionals, as discussed in this study, is an effective strategy with a high utility value. More importantly, this system enables PVPs to be collected regularly, consistently, continuously, and more importantly, sustainably. As Brouwers et al demonstrated, medical professionals are important stakeholders in healthcare, ${ }^{35}$ and they are a group of people with significant impact on improving 
present medical practices and developing new evidence for future medical practices.

Furthermore, a system in which PVPs are collected through a wide variety of medical professionals with different perspectives would enable the collection of a broad range of PVPs simultaneously. This system would be helpful for using PVPs to develop recommendations for clinical practice guidelines and solve the existing nationwide evidence-practice gap. ${ }^{36-39}$ Even more importantly, collecting PVPs through medical staff would enhance their sensitivity in interactions with patients/families about their values, desires, and experiences. This could ultimately lead to better interactions with patients/families and thereby improve their quality of life, ${ }^{40,41}$ which is not possible through the electronic collection of PVPs from patients/families.

\section{Limitations}

Despite its strengths, this study has some limitations. The first is the indirect way PVPs were collected, as mentioned in the discussion. Medical staff could have emphasized certain PVPs based on their unique concerns and individual medical experiences, while other PVPs that were less related to their medical specialties or interests may have been neglected. Second, collecting PVPs in a simple statement cannot completely capture the backgrounds of patients/families regarding "what was happening to them." Although the questionnaire's simplicity was intended to reduce the respondents' burden, it might have led to a loss of accuracy in the expressed situation. Third, contrary to the second limitation, collecting PVPs in a free text format would involve considerable time with respect to analyses and provision of an overview. Nevertheless, a free text style would enable the collection of the precise voices of patients/families in their clinical settings, even when collected by medical staff.

\section{Conclusions}

To enhance patients' adherence to treatments and to improve their subsequent satisfaction, it is crucial for health professionals to understand PVPs. It is also important to collect PVPs in timely manner to reflect issues regularly and continuously within a rapidly changing medical environment. This study suggests that collecting PVPs through nationwide cancer-specialized medical staff might be an efficient way to understand the specific requirements of patients/families. It would also be possible to document PVP trends according to changes in the environments of patients/families by collecting PVPs regularly and continuously. PVPs collected could also be utilized for developing cancer information resources for both patients/families and medical staff by suggesting important clinical questions that require answers. This initiative can support more effective patient-clinician communication and improve the healthcare environment for patients/families and medical staff.

\section{Abbreviations}

PVP, Patients' and families' views and preferences; CISC, Cancer Information and Support Centers; JACCC, Japanese Association of Clinical Cancer Centers; DCCH, Designated cancer care hospital; NCC-CIS, Center for Cancer Control and Information Services, National Cancer Center, Japan; Q \& A, Questions and answers.

\section{Informed Consent and Ethical Approval}

All procedures performed in the study were in accordance with the ethical standards of the institutional and/or national research committee and the 1964 Helsinki Declaration and its later amendments or comparable ethical standards. Ethical approval was judged as not necessary by the Medical Ethical Committee of the National Cancer Center (6000-017).

\section{Acknowledgments}

The authors would like to thank the medical staff in the 32 hospitals belonging to the Japanese Association of Clinical Cancer Centers and the Cancer Information and Support Centers in designated cancer care hospitals who participated in this study. The authors wish to acknowledge Ms. Otome Watanabe and Dr. Yoshiko Ikeguchi of the NCCCIS for their useful discussions regarding developing clinical questions. The authors are also grateful to Dr. Takeo Nakayama for his valuable insights on the manuscript. We would like to thank Editage for English language editing.

\section{Funding}

This study was funded by the Health and Labor Sciences Research Grant awarded to Tomoko Takayama toward "Establishing a sustainable system of cancer information and support center system for the future (H29Cancer Control-005)" and to Fumihiko Wakao toward "Establishing a system for prompt and timely provision 
of the evidence-based cancer information to the public (R2-Cancer Control-20EA1008)".

\section{Disclosure}

The authors declare no conflicts of interest.

\section{References}

1. Barbosa CD, Balp B, Kulich K, Germain N, Rofail D. A literature review to explore the link between treatment satisfaction and adherence, compliance, and persistence. Patient Prefer Adherence. 2012;6:39-48. doi:10.2147/PPA.S24752

2. Belinchón I, Rivera R, Blanch C, Comellas M, Lizán L. Adherence, satisfaction and preferences for treatment in patients with psoriasis in the European union: a systematic review of the literature. Patient Prefer Adherence. 2016;10:2357-2367. doi:10.2147/PPA.S117006

3. Joosten EAG, DeFuentes-Merillas L, de Weert GH, Sensky T, van der Staak CPF, de Jong CAJ. Systematic review of the effects of shared decision-making on patient satisfaction, treatment adherence and health status. Psychother Psychosom. 2008;77(4):219-226. doi:10.1159/000126073

4. Hua A, Sesto ME, Zhang X, Wassenaar TR, Tevaarwerk AJ. Impact of survivorship care plans and planning on breast, colon, and prostate cancer survivors in a community oncology practice. J Cancer Educ. 2020;35(2):249-255. doi:10.1007/s13187-018-1457-y

5. Harrison JD, Young JM, Price MA, Butow PN, Solomon MJ. What are the unmet supportive care needs of people with cancer? A systematic review. Support Care Cancer. 2009;17(8):1117-1128. doi:10.1007/s00520-009-0615-5

6. Harrington CB, Hansen JA, Moskowitz M, Todd BL, Feuerstein M. It's not over when it's over: long-term symptoms in cancer survivorsa systematic review. Int J Psychiatry Med. 2020;40(2):163-181. doi:10.2190/PM.40.2.c

7. Stein KD, Syrjala KL, Andrykowski MA. Physical and psychological long-term and late effects of cancer. Cancer. 2008;112 (S11):2577-2592. doi:10.1002/cncr.23448

8. Cormie P, Zopf EM, Zhang X, Schmitz KH. The impact of exercise on cancer mortality, recurrence, and treatment-related adverse effects. Epidemiol Rev. 2017;39(1):71-92. doi:10.1093/epirev/mxx007

9. Ebenau A, van Gurp J, Hasselaar J. Life values of elderly people suffering from incurable cancer: a literature review. Patient Educ Couns. 2017;100(10):1778-1786. doi:10.1016/j.pec.2017.05.027

10. Rogith D, Yusuf RA, Hovick SR, et al. Patient knowledge and information-seeking about personalized cancer therapy. Int $J$ Med Inform. 2016;88:52-57. doi:10.1016/j.ijmedinf.2016.01.005

11. Blanch-Hartigan D, Chawla N, Moser RP, Finney Rutten LJ, Hesse BW, Arora NK. Trends in cancer survivors' experience of patient-centered communication: results from the health information national trends survey (HINTS). $J$ Cancer Surviv. 2016;10 (6):1067-1077. doi:10.1007/s11764-016-0550-7

12. Higashi T, Nakamura F, Shibata A, Emori Y, Nishimoto H. The national database of hospital-based cancer registries: a nationwide infrastructure to support evidence-based cancer care and cancer control policy in Japan. Jpn J Clin Oncol. 2014;44(1):2-8. doi:10.1093/jjco/hyt013

13. Linn AJ, van der Goot MJ, Brandes K, van Weert JCM, Smit EG. Cancer patients' needs for support in expressing instrumental concerns and emotions. Eur J Cancer Care. 2019;28(6):e13138. doi:10.1111/ecc.13138

14. Underhill ML, Sheldon LK, Halpenny B, Berry DL. Communication about symptoms and quality of life issues in patients with cancer: provider perceptions. $J$ Cancer Educ. 2014;29(4):753-761. doi:10.1007/s13187-014-0651-9

15. Japanese association of clinical cancer centers: member of Japan association of clinical cancer centers; 2020. Available from: http:// www.zengankyo.ncc.go.jp/. Accessed March 19, 2020.
16. Takayama T, Yamaki C, Hayakawa M, Higashi T, Toh Y, Wakao F. Development of a new tool for better social recognition of cancer information and support activities under the national cancer control policy in Japan. J Public Health Manag Pract. 2020. doi:10.1097/ PHH.0000000000001155

17. Littelejohn SW, Foss KA. The input-process-output model. In: Theories of Human Communication. 10th ed. Long Grove, Illinois: Waveland Press; 2010:268-273.

18. Cancer mortality (1958-2018). Cancer registry and statistics. cancer information service, national cancer center, Japan (vital statistics of Japan); 2020. Available from: https://ganjoho.jp/reg_stat/statistics/dl/ index.html. Accessed March 19, 2020.

19. Hsieh H-F, Shannon SE. Three approaches to qualitative content analysis. Qual Health Res. 2005;15(9):1277-1288. doi:10.1177/ 1049732305276687

20. Hewitt ME, Greenfield S, Stovall E. National Cancer Policy Board. From Cancer Patient to Cancer Survivor: Lost in Transition. Washington, DC: National Academies Press; 2006.

21. Jo HS, Park K, Jung SM. A scoping review of consumer needs for cancer information. Patient Educ Couns. 2019;102(7):1237-1250. doi:10.1016/j.pec.2019.02.004

22. Questions and answers for "tingling/numbness/pain" cancer information service, national cancer center, Japan; 2020. Available from: https:/ganjoho.jp/public/support/condition/peripheral_neuropathy/ pnqa.html. Accessed January 9, 2021.

23. Park ER, Norris RL, Bober SL. Sexual health communication during cancer care. Barriers and recommendations. Cancer J. 2009;15 (1):74-77. doi:10.1097/PPO.0b013e31819587dc

24. Dyer K, Das Nair R. Why don't healthcare professionals talk about sex? A systematic review of recent qualitative studies conducted in the United Kingdom. $J$ Sex Med. 2019;10(11):2658-2670. doi:10.1111/j.1743-6109.2012.02856.x

25. Magnan MA, Reynolds KE, Galvin EA. Barriers to addressing patient sexuality in nursing practice. Medsurg Nurs. 2005;14(5):282-289; quiz290.

26. Kim K, Kim JS. Intervention for patient reported urinary symptoms in prostate cancer survivors: systematic review. J Cancer Surviv. 2017;11(5):643-654. doi:10.1007/s11764-017-0637-9

27. Vistad I, Fosså SD, Dahl AA. A critical review of patient-rated quality of life studies of long-term survivors of cervical cancer. Gynecol Oncol. 2006;102(3):563-572. doi:10.1016/j.ygyno.2006.03.050

28. Bjoern MX, Nielsen S, Perdawood SK. Quality of life after surgery for rectal cancer: a comparison of functional outcomes after transanal and laparoscopic approaches. J Gastrointest Surg. 2019;23 (8):1623-1630. doi:10.1007/s11605-018-4057-6

29. Zullo MA, Manci N, Angioli R, Muzii L, Panici PB. Vesical dysfunctions after radical hysterectomy for cervical cancer: a critical review. Crit Rev Oncol Hematol. 2003;48(3):287-293. doi:10.1016/s10408428(03)00125-2

30. Olsen AL, Smith VJ, Bergstrom JO, Colling JC, Clark AL. Epidemiology of surgically managed pelvic organ prolapse and urinary incontinence. Obstet Gynecol. 1997;89(4):501-506. doi:10.1016/ S0029-7844(97)00058-6

31. Hershman DL, Lacchetti C, Dworkin RH, et al. Prevention and management of chemotherapy-induced peripheral neuropathy in survivors of adult cancers: American society of clinical oncology clinical practice guideline. J Clin Oncol. 2014;32(18):1941-1967. doi:10.1200/JCO.2013.54.0914

32. Colvin LA. Chemotherapy-induced peripheral neuropathy: where are we now? Pain. 2019;160(Supp11):S1-S10. doi:10.1097/j. pain.0000000000001540

33. Kotronoulas G, Kearney N, Maguire R, et al. What is the value of the routine use of patient-reported outcome measures toward improvement of patient outcomes, processes of care, and health service outcomes in cancer care? A systematic review of controlled trials. J Clin Oncol. 2014;32(14):1480-1501. doi:10.1200/JCO.2013.53.5948 
34. Harris J, Cheevers K, Armes J. The emerging role of digital health in monitoring and supporting people living with cancer and the consequences of its treatments. Curr Opin Support Palliat Care. 2018;12 (3):268-275. doi:10.1097/SPC.0000000000000362

35. Brouwers MC, Kho ME, Browman GP, et al. AGREE II: advancing guideline development, reporting and evaluation in health care. $J$ Clin Epidemiol. 2010;63(12):1308-1311. doi:10.1016/j.jclinepi.2010.07.001

36. Krahn M, Naglie G. The next step in guideline development: incorporating patient preferences. JAMA. 2008;300:436-438. doi:10.1001/ jama.300.4.436

37. Chong CAKY, Chen IJ, Naglie G, Krahn MD. How well do guidelines incorporate evidence on patient preferences? J Gen Intern Med 2009;24(8):977-982. doi:10.1007/s11606-009-0987-8

38. Selva A, Sanabria AJ, Pequeño S, et al. Incorporating patients' views in guideline development: a systematic review of guidance documents. $J$ Clin Epidemiol. 2017;88:102-112. doi:10.1016/j. jclinepi.2017.05.018
39. Brouwers MC, Vukmirovic M, Spithoff K, Zwaal C, McNair S, Peek N. Engaging cancer patients in clinical practice guideline development: a pilot study. Curr Oncol. 2018;25(4):250-256. doi:10.3747/ co. 25.3943

40. Epstein RM, Street RL. Shared mind: communication, decision making, and autonomy in serious illness. Ann Fam Med. 2011;9 (5):454-461. doi:10.1370/afm. 1301

41. Walsh J, Young JM, Harrison JD, et al. What is important in cancer care coordination? A qualitative investigation. Eur J Cancer Care. 2011;20(2):220-227. doi:10.1111/j.1365-2354.2010.01187.x
Patient Preference and Adherence

\section{Publish your work in this journal}

Patient Preference and Adherence is an international, peer-reviewed, open access journal that focusing on the growing importance of patient preference and adherence throughout the therapeutic continuum. Patient satisfaction, acceptability, quality of life, compliance, persistence and their role in developing new therapeutic modalities and compounds to optimize clinical outcomes for existing disease

\section{Dovepress}

states are major areas of interest for the journal. This journal has been accepted for indexing on PubMed Central. The manuscript management system is completely online and includes a very quick and fair peer-review system, which is all easy to use. Visit http:// www.dovepress.com/testimonials.php to read real quotes from published authors. 